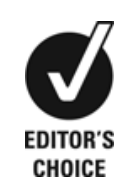

Department of Health, Research Institute for Tropical Medicine, Manila, Philippines ${ }^{2}$ Menzies Health Institute Queensland, Queensland, Australia

\section{Correspondence to} Professor Allen Ross, a.ross@griffith.edu.au

Accepted 9 February 2015

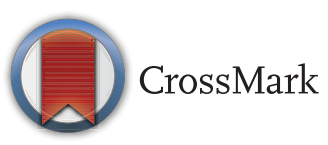

To cite: Vinluan ML, Olveda RM, Olveda DU, et al. BMJ Case Rep Published online: [please include Day Month Year] doi:10.1136/bcr-2014208197

\title{
Access to essential paediatric eye surgery in the developing world: a case of congenital cataracts left untreated
}

\author{
Marilyn L Vinluan, ${ }^{1}$ Remigio M Olveda, ${ }^{1}$ David U Olveda, ${ }^{2}$ Delia Chy, ${ }^{1}$ Allen G Ross ${ }^{2}$
}

\section{SUMMARY}

Childhood cataracts are a major cause of treatable blindness. Early recognition, surgical intervention and appropriate follow-up after surgery can result in good visual outcomes. However, several factors may impact on the availability of such services, including lack of an available, affordable and accessible comprehensive eye care centre, financial limitations affecting coverage by the national healthcare provider, and household socioeconomic status. We report a case of congenital cataracts in a 12-year-old male adolescent from Northern Samar, the Philippines, who was left blind since birth. This case highlights the disparities in essential health services in the developing world and the challenges patients face in getting the care they need.

\section{CASE PRESENTATION}

A 12-year-old Filipino boy, living in a remote rural village in Palapag, Northern Samar, the Philippines, (figure 1) presented with bilateral vision loss. On eye examination, opacities were noted in both lenses and the patient had only minimal light perception in his eyes. The rest of the physical examination was within normal limits.

The patient was born full term to a then 40-year-old G6P5 (5-0-0-5) mother via cephalic spontaneous vaginal delivery. The birthing process was facilitated by a traditional birth attendant ('hilot') at home. The mother did not receive prenatal care during this pregnancy but denied having measles or chicken pox while carrying her baby. The labour was said to be uncomplicated and the traditional birth attendant did not report any unusual findings in the newborn. The patient has completed his immunisations and developmental milestones were appropriate for his age. Family history was unremarkable for childhood-onset cataracts. Neither the patient's parents nor his siblings presented with the same condition.

The visual loss was initially noted by the mother when she observed the boy bumping into things at 1 year of age. A village health worker noted opacities on both lenses at 2 years of age. Oral vitamin A was then administered and the mother was advised to bring the child to the local health centre (approximately $10 \mathrm{~km}$ away) for further evaluation. There were no other subjective complaints.

The patient is the youngest of six children (the fifth child died at the age of 5). His 55 -year-old mother is a housewife and his 69-year-old father is a copra (dried coconut kernel) farmer. Both parents received only primary education. The father is the sole breadwinner and earns about PHP3000 a month (US\$67). The patient has stopped attending school and has only reached the third level of primary education.

The patient was seen by the rural health unit doctor when he was 5 years old. The initial diagnosis was bilateral congenital cataracts and the patient was referred to an ophthalmologist. However, due to the family's financial constraints and lack of funding from the national healthcare provider, Philhealth, the patient remained untreated until the age of 12 . However, a private donor (AR) working in the area offered to pay for the operation. The patient was brought to a private eye institute in the provincial capital, Catarman, where he underwent cataract surgery on his right eye (figure 2). No complications were noted after the procedure and the visual acuity of the operated eye has improved greatly.

Due to a number of socioeconomic factors, the patient was unable to attend follow-up after surgery. Approximately 3 months after the procedure, the patient started to complain of eye pain in his right eye. The visual acuity of the right eye is limited to finger counting at $4 \mathrm{~m}$. There is minimal light perception in the left eye. No nystagmus was seen. The patient is scheduled for cataract surgery on his left eye in 2015 and his right eye will be reassessed at that time.

\section{GLOBAL HEALTH PROBLEM LIST}

- Childhood cataracts remain a major global health problem in the developing world.

- Paediatric cataracts need early recognition and surgical intervention to ensure good clinical outcomes.

- Lack of provision of essential health services by national healthcare providers and the socioeconomic status of families impact directly on patient health-seeking behaviours.

- Increasing awareness of childhood cataracts and cataract surgery among families and health workers through public education and training may help children access timely eye care in rural and remote areas.

- A national healthcare policy is needed to ensure that low-income patients can access affordable medical and surgical services.

\section{GLOBAL HEALTH PROBLEM ANALYSIS}

Cataracts remain the leading cause of blindness in middle- and low-income countries. ${ }^{1}$ Cataract is 


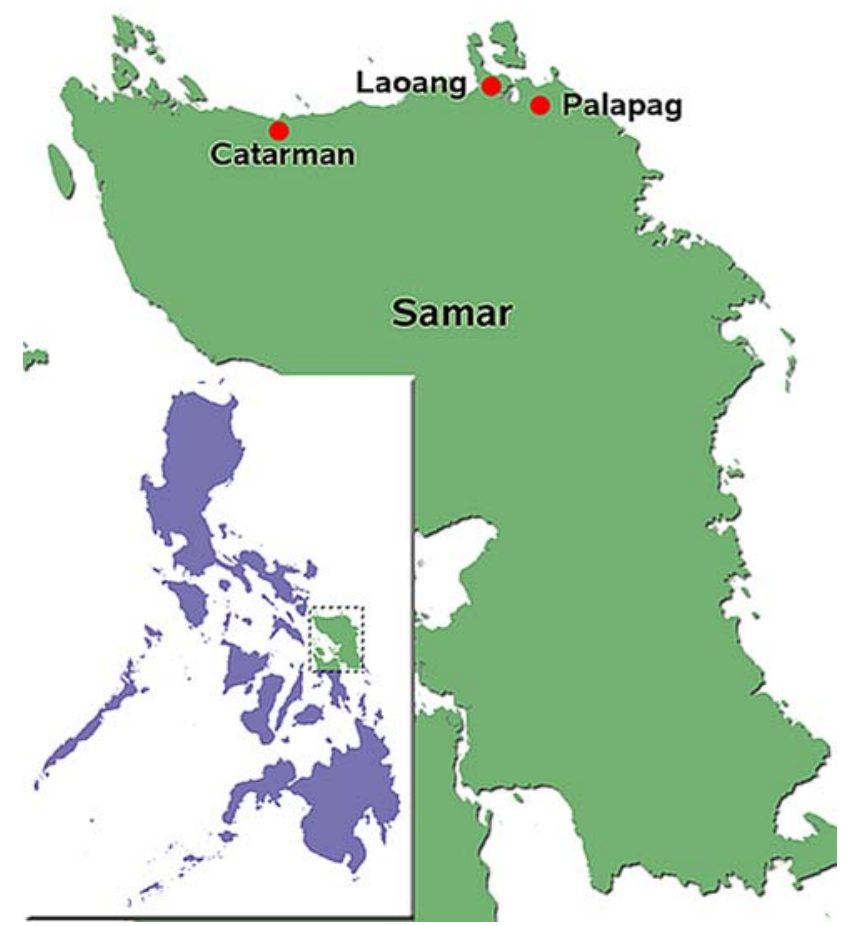

Figure 1 Map showing the location of Palapag in Northern Samar, the Philippines.

defined as any opacity or cloudiness of the lens, although clinically it frequently refers to opacities that diminish visual acuity. The elderly are more commonly affected with cataracts, but they also occur in a small percentage of the paediatric population. ${ }^{2}$ Childhood cataracts are often referred to as either congenital (when recognised at birth or within the first year) or developmental (cataracts leading to reduction in vision after 1 year of age). ${ }^{3}$ Although congenital cataracts may have various causes including intrauterine infections, metabolic disorders and genetically transmitted syndromes, ${ }^{2}$ in many children the aetiology is not identified; however, autosomal dominant inheritance can be seen. ${ }^{4}$ In a review of childhood cataract cases in the Philippines, $61 \%$ of cases were idiopathic, while rubella infection and familial causes accounted for $20.5 \%$ and $1.4 \%$ of index cases, respectively. ${ }^{5}$ Early diagnosis is essential for appropriate and timely intervention and good visual function. Visual outcome is largely dependent on the timing of surgery when dense cataracts are present. Good results have been reported in children undergoing surgery before 6 weeks of age for unilateral cataract and before 10 weeks of age in bilateral cases. Placement of an artificial intraocular lens implant after removal of the cataract has become established practice in children over 2 years of age. However, despite early surgery and aggressive optical rehabilitation, children may still develop deprivation amblyopia, nystagmus, strabismus and glaucoma. 4

The diagnosis and management of congenital cataracts have vastly improved over the past 30 years, with a concurrent improvement in the visual outcomes of affected children. ${ }^{4}$ The Philippines, as a signatory to the global initiative for the elimination of avoidable blindness 'Vision 2020-The Right to Sight', released guidelines for the implementation of the National Prevention of Blindness Program in 2004. One of the general objectives of the programme was to increase the cataract surgical rate from 730 to 2500 per million population by 2010 . Specific objectives were to: (1) conduct 74000 good outcome cataract surgeries by 2010 ; (2) ensure that all health centres are actively linked to a cataract referral centre by 2008; (3) advocate for the full coverage of cataract surgeries by Philhealth; (4) establish provincial sight preservation committees in at least $80 \%$ of provinces by 2010; (5) mobilise and train at least one primary eye care worker per barangay (village) by 2010; (6) mobilise and train at least one mid-level eye care health worker per municipality by 2010 ; (7) train at least 500 ophthalmologists in appropriate techniques and technology for cataract surgery; (8) develop a quality assurance system for all ophthalmology service facilities by 2008; and (9) ensure that 76 provincial, 16 regional and 56 Department Of Health retained hospitals are equipped with the appropriate technology for cataract surgery. The programme also aimed to reduce the prevalence of visual disability in children by 2010 by identifying such children in the community for timely intervention, improving the ability of $90 \%$ of health workers to identify and treat visual disability in children by 2010 , and establishing a fully equipped primary eye care facility in each municipality by $2008 .^{6}$ This case illustrates that a decade after the programme was implemented, many factors still prevent patients in rural and remote areas from accessing these essential services.

Early recognition of childhood cataracts is critical in order to shorten the time between the onset of visually impairing cataracts and surgery. Congenital cataracts are more likely to develop into mature cataracts, leading to severe visual deprivation, than developmental cataracts where the cataract may develop more gradually. Regardless of the type of cataract, early presentation is important for visual outcomes. ${ }^{3}$ In this boy's case, there was a delay of 12 years, which is much longer than the mean delay of 3 years among rural Tanzanian children with both congenital and developmental cataracts. ${ }^{3}$

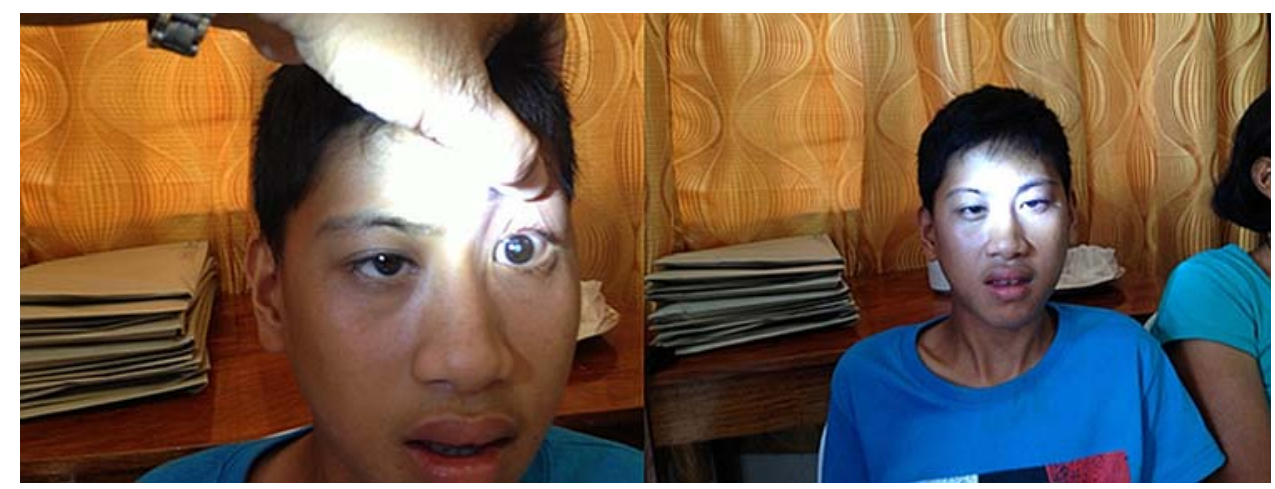

Figure 2 Images showing a congenital cataract in the left eye of a 15-year-old male Filipino patient. Note that the right eye was operated on successfully in 2013. 
The delay in the detection of the condition and the late presentation to care can be attributed to several socioeconomic factors; however, the primary constraints were the family's limited household resources and the partial coverage provided by the national healthcare provider (Philhealth). Under otherwise equal conditions, a higher income in developing countries is associated with more frequent and more intensive use of health services in both the private and public sectors. ${ }^{7}$ The mother, in this case, did not have prenatal care and had opted to have the patient delivered at home with the help of a traditional birth attendant instead of a doctor or midwife. The latter could have performed a thorough examination of the newborn, which may have led to early detection of the patient's condition.

The family's low income delayed the child's presentation for surgery. First and foremost, the family had to deal with the cost of the actual surgery itself. Since there is no tertiary government hospital in the area offering cheaper eye care services (underscoring the lack of availability of specialist health services in poor areas), the patient was referred to a private eye institute in the provincial capital. The cost of cataract surgery on one eye in this private eye centre was PHP25000 (US\$568), about eight times the monthly income of the patient's family. This emphasises that health sector reforms begun in 2000 have had little or no impact on a hospital network dominated by high-end forprofit private institutions. ${ }^{8}$ Out-of-pocket (OOP) payments are still the main method of financing healthcare in the Philippines. $^{8}$ Philhealth covers bilateral cataract surgery under two separate packages at a cost of PHP16000 (US\$364) for each package. ${ }^{9}$ The family of our patient was required to make an OOP payment of PHP9000 (US\$204), which was still clearly unaffordable.

In addition to charges levied by the healthcare provider for cataract surgery, travel expenses and foregone earnings are important costs that should also be considered. In rural areas, distances to healthcare facilities and poor road conditions mean that it takes considerable time, effort and expense to even reach the site of healthcare delivery. ${ }^{10}$ The distance from the family's home to the municipal healthcare facility was one of the reasons why there was a delay in bringing the patient to the doctor at local health unit. The patient has to cross a river and travel a distance by land just to be seen by the local doctor, which imposes an additional financial burden on the family considering that they have barely enough for their daily food needs. When the patient was referred to an ophthalmologist in the city (Catarman) for a check-up, the delay was due to the same reasons. The family live on an island and the patient has to travel by boat (US\$14) for almost an hour followed by another $2 \mathrm{~h}$ of travel by land (US\$23). Surgery alone will have limited value if postoperative follow-up is poor. Improved follow-up enables children to receive the spectacles and low vision devices necessary for visual rehabilitation. ${ }^{11}$ One study cited that close proximity to a hospital was an independent predictor of good follow-up in both the 2- and 10-week periods after cataract surgery. $^{12}$

Knowledge, literacy and education, whose levels tend to be lower among the poor, are key determinants of household income. ${ }^{7}$ In this case, the low educational attainment of both parents affected their health-seeking behaviour for their child's condition. They considered it was not life-threatening, and hence the lack of urgency to have him assessed by a specialist. Their understanding of benefit in terms of increased productivity of patients after surgery was limited. Furthermore, knowledge levels are also inadequate in the community. Village health workers failed to identify childhood cataracts and misdiagnosed it as xerophthalmia because they are not routinely trained to detect such conditions. In a study conducted in Tanzania, $88 \%$ of health workers recognised cataract in a picture, 63\% knew that it required surgery but only 50\% realised surgery was urgent. ${ }^{13}$ Health workers in the Philippines probably know less about childhood cataracts than their Tanzanian counterparts. In sum, a number of socioeconomic factors contributed to the delay in the surgical intervention required in this case. However, we are following up this patient to ensure he receives the quality of care he deserves.

\section{Learning points}

- Cataracts, although affecting only a small percentage of the paediatric population, are a major cause of treatable blindness in children.

- Childhood cataracts, regardless of whether if they are congenital or developmental, need early recognition and surgical intervention to ensure good clinical outcomes.

- The provision of essential health services by national healthcare providers (eg, Philhealth) and the socioeconomic status of families impact directly on patient health-seeking behaviours.

- Increasing awareness of childhood cataracts and cataract surgery among families and health workers through public education and training may help children access timely eye care in rural and remote areas.

- A national health care policy needs to be developed to ensure that low-income patients have access to affordable medical and surgical services.

Competing interests None.

Patient consent Obtained.

Provenance and peer review Not commissioned; externally peer reviewed.

\section{REFERENCES}

1 WHO Fact Sheet No 282. 2014. http://www.who.int/mediacentre/factsheets/fs282/en/

2 Wirth MG, Russell-Eggitt IM, Craig JE, et al. Aetiology of congenital and paediatric cataract in an Australian population. Br J Ophthalmol 2002;86:782-6.

3 Mwende J, Bronsard A, Mosha M, et al. Delay in presentation to hospital for surgery for congenital and developmental cataract in Tanzania. Br J Ophthalmol 2005;89:1478-82.

4 Chan WH, Biswas S, Ashworth JL, et al. Congenital and infantile cataract: aetiology and management. Eur J Pediatr 2012;171:625-30.

5 Tecson JV III, Santiago AP. Profile of childhood cataract cases at the Philippine General Hospital. Philippine J Ophthalmol 2004:29:140-3.

6 National Prevention of Blindness Program. In: ed. Philippines: Department of Health, 2004. http://www.doh.gov.ph/content/national-prevention-blindness-program.html

7 Wagstaff A. Poverty and health sector inequalities. Bull World Health Organ 2002:80:97-105.

8 Health Service Delivery Profile Philippines. Collaboration between WHO and Department of Health, Philippines, 2012. http://www.wpro.who.int/health_services/ service_delivery_profile_philippines.pdf

9 Philhealth Circular No. $0017 \mathrm{~s}-2013$. Exemption of Cataract Surgery to the Rule on Single Period of Confinement. Philippine Health Insurance Corporation, 2013.

10 O'Donnell O. Access to health care in developing countries: breaking down demand side barriers. Cadernos de Salude Publica 2007;23:2820-34.

11 Kishiki E, Shirima S, Lewallen S, et al. Improving postoperative follow-up of children receiving surgery for congenital or developmental cataracts in Africa. J AAPOS 2009;13:280-2

12 Eriksen JR, Bronsard A, Mosha M, et al. Predictors of poor follow-up in children that had cataract surgery. Ophthalmic Epidemiol 2006;13:237-43.

13 Kishiki E, Hogeweg M, Dieleman M, et al. Is the existing knowledge and skills of health workers regarding eye care in children sufficient to meet needs? Int Health 2012;4:303-6 


\section{Global health}

Copyright 2015 BMJ Publishing Group. All rights reserved. For permission to reuse any of this content visit http://group.bmj.com/group/rights-licensing/permissions.

BMJ Case Report Fellows may re-use this article for personal use and teaching without any further permission.

Become a Fellow of BMJ Case Reports today and you can:

- Submit as many cases as you like

- Enjoy fast sympathetic peer review and rapid publication of accepted articles

- Access all the published articles

- Re-use any of the published material for personal use and teaching without further permission

For information on Institutional Fellowships contact consortiasales@bmjgroup.com

Visit casereports.bmj.com for more articles like this and to become a Fellow 